\title{
AGRICULTURA PREHISPÁNICA EN YASYAMAYo (VALlE DE SANTA MaRÍA, TUCUMÁN, ARGENTINA)
}

\author{
Jimena Roldán ${ }^{1}$, Marta Vattuone ${ }^{2}$, María Marta Sampietro 3
}

\section{* Introducción}

Resumen

En Argentina son escasos los estudios sobre la actividad agrícola prehispánica y prácticamente inexistentes aquellos que la abordan desde una perspectiva geoarqueológica. El objetivo de este trabajo es determinar las alteraciones antrópicas producidas por el uso sostenido de los campos de cultivos prehispánicos tardíos ubicados en Yasyamayo, y su relación con las condiciones ambientales típicas del momento de ocupación. Para ello se utilizaron métodos provenientes de las geociencias tales como determinaciones de $\mathrm{pH}$, textura, color, estructura, porcentaje de materia orgánica, fósforo orgánico, fósforo

disponible, calcio, manganeso, cobre y hierro disponibles. Como resultado pudo observarse una clara diferencia entre las tierras bajo cultivo y aquellas naturales. Incluso se registró la utilización de abono para la mantención de los campos agrícolas en condiciones medioambientales adversas.

Palabras claves: geoarqueología - geobioquímica - economía de subsistencia - Desarrollos Regionales.

In Argentina, the prehispanic agricultural activity, is not the most popular issue to investigate and almost nobody study it from a geoarchaeological perspective. Therefore our objective was to determinate the anthropic modification produced by the sustained use of prehispanic cultivated fields located at Yasyamayo (Tucumán, Argentina), and their relationship with the climatic conditions at the moment of occupation. To accomplish it we used methods from the geoscience such as $\mathrm{pH}$, texture, color, structure, bulk density, organic

phosphorous, calcium, and available phosphorous, manganese, cupper and iron. We could determinate a clear distinction between agricultural and natural lands. It was even possible to recognize the use of organic fertilizer in the agricultural areas.

Key words: geoarchaeology - geobiochemistry - subsistence economy Regional Development period.
Ente los primeros arqueólogos argentinos, el estudio de los aspectos productivos prehispánicos, como la actividad agrícola, no fue un tema que les despertara curiosidad, ya sea por falta de interés o por la carencia de métodos y técnicas que les permitieran investigarlos. Con el paso del tiempo el enfoque teórico fue cambiando, permitiendo utilizar métodos y técnicas provenientes de otras disciplinas, situación que facilitó abordar y solucionar problemas arqueológicos que de otra forma no hubiesen podido resolverse.

Es por ello que el objetivo de este trabajo es determinar las alteraciones antrópicas producidas por el uso sostenido de los campos de cultivo prehispánicos tardíos, ubicados en el glacis cubierto de Yasyamayo (valle de Santa María, Tucumán) y su relación con las condiciones ambientales típicas del momento de ocupación.

El área estudiada es una geoforma conocida como glacis cubierto de Yasyamayo, ubicado en el piedemonte occidental de Cumbres Calchaquíes (Sampietro y Neder 2011), más precisamente en la porción tucumana del valle de Santa María. Este valle es una depresión ancha de fondo plano que se profundiza entre la sierra de Quilmes al oeste y el sistema Aconquija-Cumbres Calchaquíes al este. El agua corre de sur a norte, en dirección opuesta al declive regional predominante. El fondo del valle de inclina entre 1900 y 1600 m.snm (Strecker 1987). Las

Recibido: agosto 2012. Aceptado: agosto 2013.

\footnotetext{
1 Laboratorio de Geoarqueología. Facultad de Ciencias Naturales e Instituto Miguel Lillo, Universidad Nacional de Tucumán. General López 3456, dpto. 7. CP. 300o. Santa Fe, ARGENTINA. Email: jimena_roldan@yahoo.com

2 Instituto de Estudios Vegetales, Facultad de Química, Bioquímica y Farmacia, Universidad Nacional de Tucumán - CONICET. Ayacucho 471. CP. 400o. San Miguel de Tucumán, ARGENTINA. Email: mavattu@gmail.com
} 
precipitaciones varían dependiendo de la ubicación de los cordones montañosos y la circulación de los vientos húmedos dominantes que regularmente provienen del este o del sureste; el área de estudio se ubica sobre el piedemonte más seco del valle (Figuras 1, 2, 3 y 4).

El clima regional es de tipo desértico, con una temperatura promedio anual de $18^{\circ} \mathrm{C}$ y una precipitación promedio anual de $250 \mathrm{~mm}$ (normalmente estival) (Perea 1994). El paisaje es semiárido, caracterizado por cardones, árboles y arbustos bajos, espinosos y adaptados al desierto (Cabrera 1976).

En esta región una de las culturas arqueológicas más estudiada es Santa María, propia del período de Desarrollos Regionales (950-1430 DC), que presenta una estructura socioeconómica compleja y mejor conocida que aquella de períodos anteriores. Se observan núcleos de poblaciones grandes asociados a un pucara que reúne grupos menores. Con el tiempo éstas se encuentran cada vez más fortificadas, mostrando una mayor necesidad y preocupación por protegerse. Los sistemas de subsistencia son eficientemente explotados, en algunos casos superando su capacidad ambiental. Las tecnologías como la metalurgia, alfarería y textilería están muy desarrolladas. El sistema religioso está vinculado al prestigio y poder social, en tanto los objetos de culto y algunos rituales están asociados a las actividades bélicas (Tarragó 2000; DeMarrais 2001).

\section{* Antecedentes}

Las investigaciones arqueológicas en sitios ubicados en el piedemonte occidental de Cumbres Calchaquíes son escasas. Uno de los trabajos más tempranos en la región fue el de Sosa (1996-97, 1999, 2001) quien realizó el mapeo de asentamientos tempranos y tardíos. Para ello, dividió a la zona de análisis en seis conjuntos identificando dos ejes de ocupación, el primero ubicado por debajo de la cota de los 2000 m.snm hasta el río Santa María, y el otro por encima de los $2300 \mathrm{~m}$.snm hasta alcanzar los

\footnotetext{
3 Laboratorio de Geoarqueología. Facultad de Ciencias Naturales e Instituto Miguel Lillo, Universidad Nacional de Tucumán - CONICET. España 2903. CP. 4000. San Miguel de Tucumán, ARGENTINA. Email: xuchitl1970@hotmail.com
}

4000 m.snm. Para el Formativo expansidió la ocupación basada en la explotación de todos los conos de deyección con posibilidades agrícolas, en muchos casos superando en extensión a la ocupación actual. Para el período de Desarrollos Regionales aumenta la densidad de ocupación en el área pedemontana dando lugar, en algunos casos, a la formación de los primeros asentamientos conglomerados caracterizados por su localización en zonas desfavorables para la agricultura pero con acceso directo a terrenos favorables para dicha práctica. La ocupación de zonas de altura es clara para esta época. Llama la atención la presencia de zonas discretas, que pueden deberse a las limitaciones de la metodología y/o a la geomorfología de la región que hace a algunos lugares más aptos para la actividad agrícola que otros, merced a la disponibilidad de agua. Finalmente, detectó la presencia de sendas que comunican diferentes zonas del piedemonte en dirección este-oeste; ello le permitió suponer la presencia de un solo grupo sociocultural disperso en toda la región de los faldeos.

Si bien el enfoque de Sosa es novedoso para la época y como primera aproximación a un área de estudio es muy útil, la falta de controles de campo hace que el trabajo esté inconcluso. Sumado a ello, actualmente tenemos mayor información relacionada con la dinámica observada en las condiciones climáticas acaecidas a lo largo del tiempo en estos valles. Por lo tanto, para que el mismo sea útil, necesita ser actualizado, incorporando datos climáticos y geológicos prehistóricos.

En respuesta a esta problemática surge el trabajo realizado por Sampietro y Neder (2011) quienes utilizaron la fotointerpretación para poder estudiar la evolución cuaternaria del paisaje en la vertiente occidental de Cumbres Calchaquíes (valle de Santa María), y cómo ésta se relacionaba con la ocupación humana prehispánica. Elaboraron un mapa litogeomorfológico que contenía las unidades geomorfológicas ordenadas cronológicamente y un mapa arqueológico para representar el lugar que los sitios arqueológicos ocupaban dentro del contexto paisajístico de cada unidad. Debido a la escala (1:5000o) en la que se trabajó, fue imposible dibujar un mapa arqueológico preciso; es por ello que se delimitaron áreas arqueológicas y se realizaron los controles de campo correspondientes. A partir de la forma y distribución de las estructuras arqueológicas observadas y de la recolección 


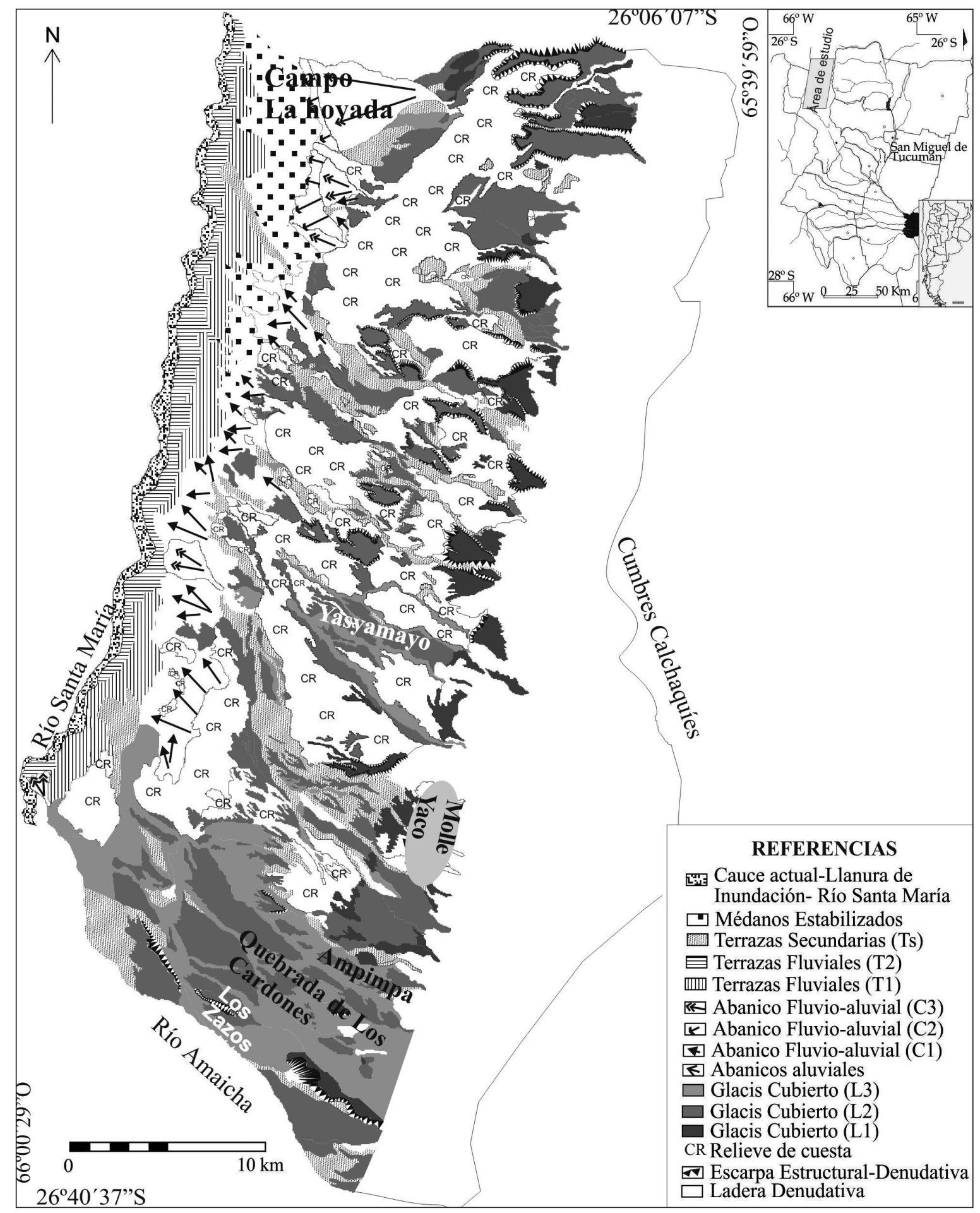

Figura 1. Mapa geomorfológico de la vertiente occidental de Cumbres Calchaquíes, valle de Santa María. Tucumán, Argentina. Modificado de Sampietro y Neder (2011). 


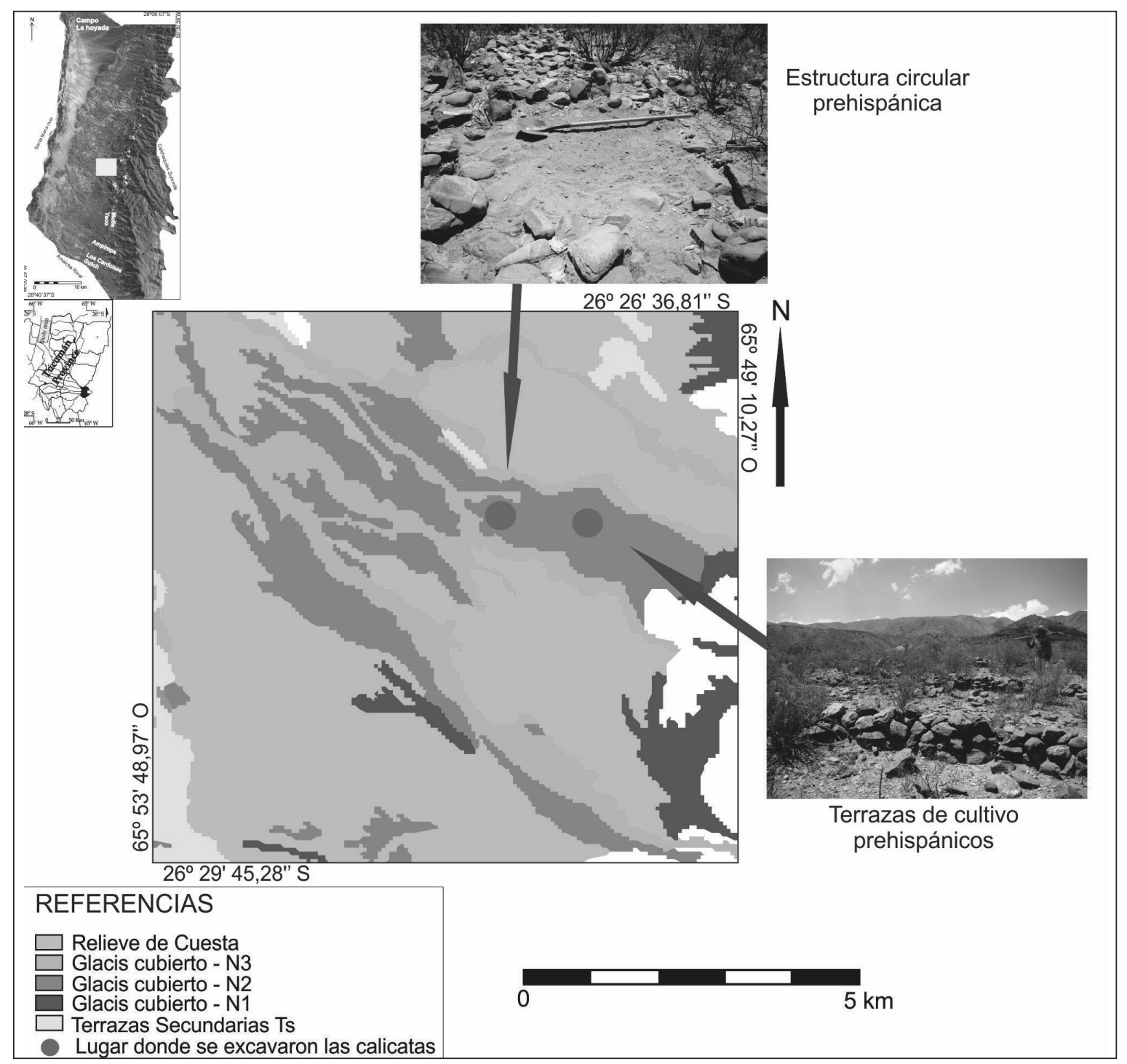

Figura 2. Mapa en detalle del glacis cubierto nivel 2 de Yasyamayo, valle de Santa María. Tucumán, Argentina.

en superficie de cerámica, pudieron establecer una cronología relativa para los sitios mapeados. Los abanicos aluviales son las únicas unidades geomorfológicas que contienen solamente estructuras del período Formativo, es decir estructuras circulares dispersas en campos de cultivo. Mientras que los glacis cubiertos (nivel 2) y laderas tenían estructuras de los períodos Formativo y Desarrollos Regionales superpuestas, las primeras reconocibles por el patrón de distribución ya especificado para los abanicos aluviales, y las segundas identificables por estructuras más bien rectangulares dispersas entre campos de cultivo (más adelante nos extenderemos en este tema) y un asentamiento semiurbano ya descrito por Rivolta (2007). El sitio de Yasyamayo pertenece a este último grupo.

A una escala menor, Rivolta (1999, 2007 y 2010) es quien tiene mayor continuidad en el trabajo arqueológico en la región. Ha estudiado sitios en las inmediaciones de la Quebrada de los Cardones y el sitio tardío Los Cardones. Referido al período Formativo describió la presencia en conos y abanicos aluviales de recintos circulares 


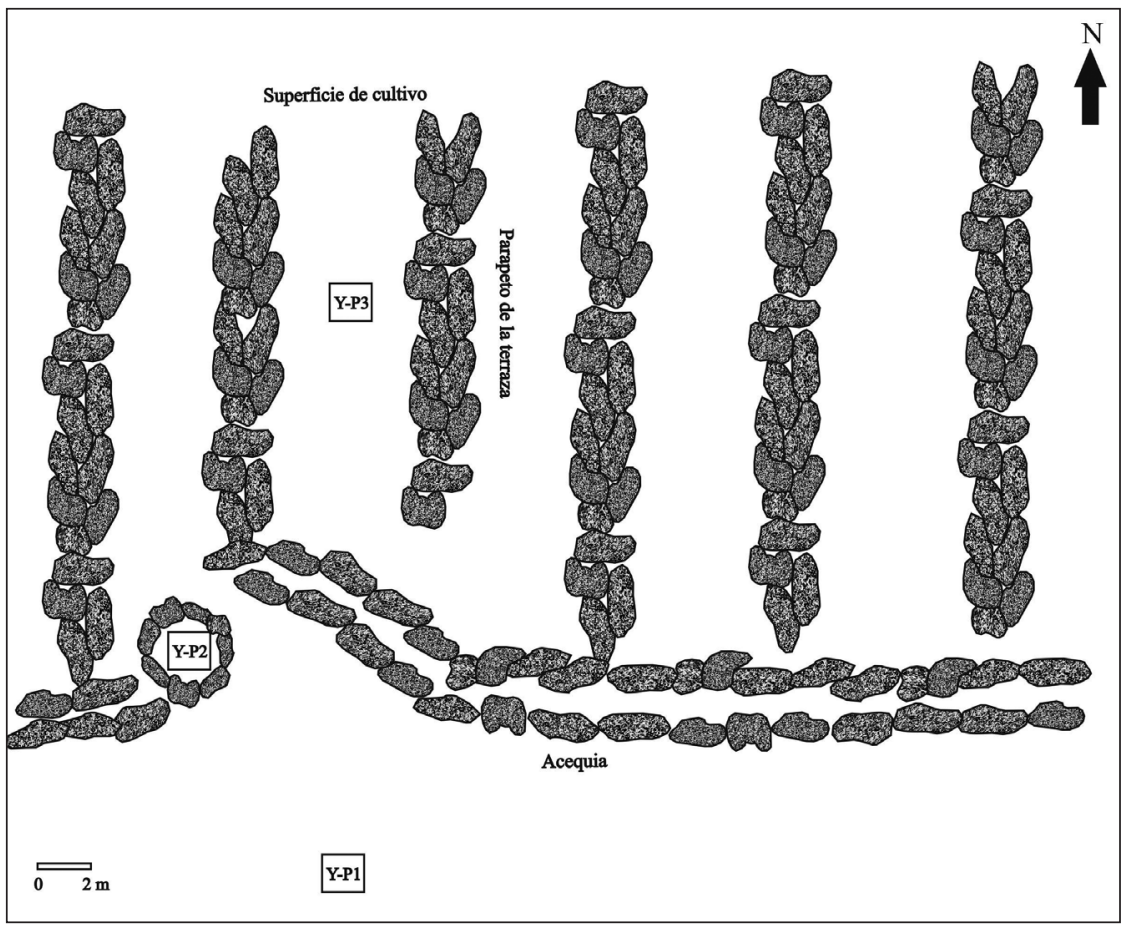

Figura 3. Croquis de la zona distal de la geoforma de Yasyamayo donde se excavaron las calicatas Y-P1, Y-P2 e Y-P3.

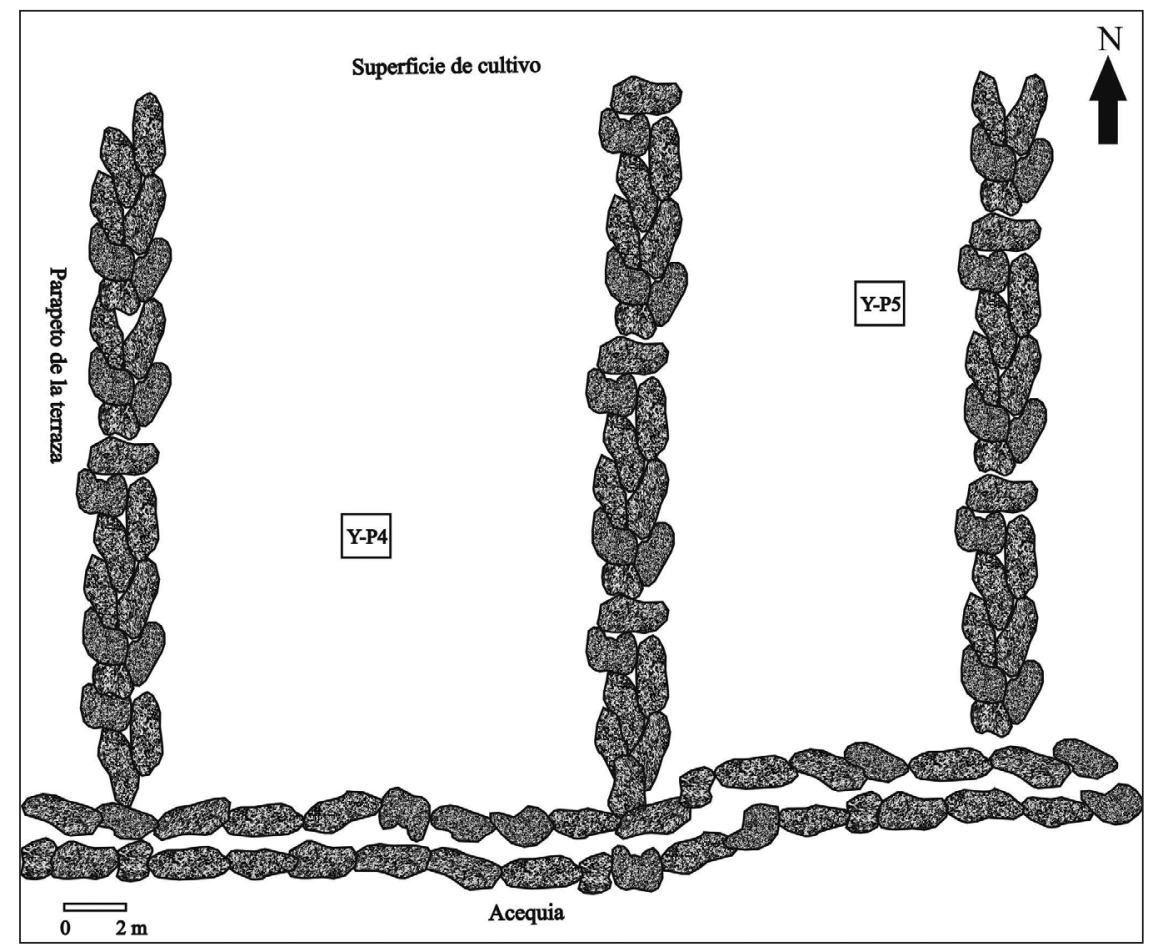

Figura 4. Croquis de la zona media de la geoforma de Yasyamayo donde se excavaron las calicatas Y-P4 e Y-P5. 
asociados entre sí formando un patrón de asentamiento disperso tipo Tafí y estructuras agrícolas asociadas a pequeñas estructuras circulares (depósitos), la cerámica encontrada fue de tipo Tafí, Ciénaga y Vaquerías. El sitio tardío (correspondiente al período de Desarrollos Regionales) fue ocupado hasta la época del contacto hispanoindígena (989-149o DC). Se definió como tal a partir del tipo y disposición de estructuras, la cerámica de filiación Santa María, Belén e Inca (Rivolta y Salazar 2007) y dataciones radiocarbónicas sobre macrorrestos vegetales. Se emplazó en las laderas y cumbres de cerros, era un conglomerado semiurbano con un trazado unilineal e irregular dividido por el río Amaicha. Internamente estaba compuesto por espacios domésticos y comunitarios. Las estructuras residenciales eran grandes rectángulos que en ocasiones tenían adosadas o incluidas una o más estructuras circulares pequeñas; en ellas no parece existir segmentación y especialización en la utilización de los espacios. Por otro lado, se observaron estructuras agrícolas al pie del cerro y próximas al sitio, como también grandes estructuras rectangulares que pudieron funcionar como corrales. En la excavación de una estructura pública se encontraron importantes cantidades de restos de maíz (Zea mays) y en una estructura doméstica se hallaron restos de poroto (Phaseolus sp.) (Rivolta 2010).

Somonte (2009) y Somonte y Baied (2011), estudian tres sitios Formativos. Campo Blanco y Bajo los Cardones están relacionados, el primero es un taller lítico utilizado desde tiempos remotos, incluyendo el Formativo, mientras que Bajo Los Cardones es un sitio con un patrón de caseríos dispersos, insertos en áreas de actividad agropastoril muy similar arquitectónicamente al sitio El Remate estudiado por Aschero y Ribotta (2007). El carácter formativo de este sitio está dado por la arquitectura y la alfarería Vaquerías, Tafí, Candelaria y Ciénaga encontrada. El sitio Planchada La Puntilla, ocupado desde el Formativo hasta el período de Desarrollos Regionales, ubicado sobre un glacis, estaba compuesto por estructuras habitacionales y una estructura en arco simple; debido a su mala conservación y a la evidencia de desmantelamiento parcial de algunas estructuras por efectos del saqueo, no pudieron definir un diseño arquitectónico homogéneo.

Otro sitio estudiado en la región es conocido por los lugareños como El Remate, ubicado cercano a la zanja de Los
Cardones (Los Zazos). Este sitio presentaba dos sectores diferenciados, uno hacia el sur y el otro hacia el norte. En el primero se encontraron unas cuantas estructuras circulares rodeadas por andenes de cultivo, mientras que en el segundo se observó una aglomeración de estructuras con una mayor complejidad en su articulación espacial. La excavación del patio de una de las estructuras, ubicada en el sector sur, mostró la existencia de dos períodos de ocupación. Las características de diseño del asentamiento eran similares a las observadas para La Bolsa (valle de Tafí) y La Ciénega (valle de la Ciénega), es decir, diferente al "patrón margarita" (sensu Aschero y Ribotta 2007).

La atención a los espacios productivos agrícolas prehispánicos es una situación bastante reciente en el Noroeste Argentino (Berberián y Nielsen 1988; Albeck 1993, 2010; Sampietro 2002; Caria et al. 2006, 2010; Korstanje 2007, 2010; Olivera et al. 2008; Roldán et al. 2008; Quesada 2010; Tchilinguirian y Olivera 2010; Williams et al. 2010, entre otros). En general, se realizaban descripciones de los mismos y se los asociaba con las estructuras domésticas y/o ceremoniales, las cuales tendían a ser el centro de estudio.

Con el tiempo el foco de interés se centró también en los espacios productivos, o agrícolas en este caso; para ello se estudió la variabilidad climática, las características paisajísticas y los suelos involucrados en la actividad agrícola, donde se detallan las características físicas y químicas de los mismos y se realizan análisis polínicos y de fitolitos. Este enfoque multidisciplinario permitió la construcción de una base de datos que ha aportado nuevos conocimientos sobre la vida campesina de los grupos prehispánicos del Noroeste Argentino, generando a su vez, un conjunto de nuevos interrogantes.

De esta forma, surge una gran cantidad de trabajos enfocados en las actividades agrícolas de los pueblos prehispánicos y en la forma que éstas se articulan con la situación social de cada grupo. Los investigadores abocados a esta tarea han usado diferentes enfoques para abordar la temática, lo cual permitió obtener puntos de vista muy originales y creativos en relación a como se articulaba la actividad agrícola a la vida social de cada comunidad.

Como ejemplo, se pueden mencionar los trabajos de Sampietro (2002) y Roldán y colaboradores (2008) en el 
valle de Tafí, que utilizaron un enfoque geoarqueológico para poder entender la dinámica pedo-paisajística ocurrida durante el Formativo en dicho valle, y así establecer el contexto medioambiental en el cual se circunscribía la vida agrícola de las poblaciones prehispánicas estudiadas. Con este enfoque pudieron conocer la variabilidad climática a lo largo de dicho período y la forma en que fueron explotados los suelos agrícolas, observándose una relación directa entre la elección de los espacios para asentarse con las condiciones paisajísticas, sin descartar la intervención de factores de tipo meramente social.

Hacia la región de Infiernillo (punto de contacto entre el valle de Tafí y el valle de Santa María), Caria y colaboradores $(2006,2010)$ estudiaron estructuras agrícolas dentro de un asentamiento formativo en el sitio Quebrada de los Corrales donde reconocen la práctica de una agricultura de secano en una región actualmente muy árida, pero que en épocas pasadas fue más húmeda, permitiendo a la población la utilización de agua meteórica, utilizando los reservorios encontrados para almacenarla y las acequias para canalizarla hacia los cultivos. En el mismo sitio, Arreguez y González (2007) y Oliszewski (2009) encuentran, dentro de una cueva, restos de cultivos domesticados como poroto común (Phaseolus vulgaris var. Vulgaris L.), zapallo (Cucurbita sp.), pseudocereales como quinoa o amaranto (Chenopodium quinoa y Amaranthus sp., respectivamente), tubérculos microtérmicos, y granos, marlos y "chala" de cuatro variedades de maíz (Zea mays) (pisingallo, morocho amarillo). En ambos casos las áreas de cultivo estaban bien definidas, gracias a la presencia de canchones, andenes y/o terrazas de cultivo construidos con material rocoso propio de la región.

Para el vecino valle de Santa María, uno de los pocos trabajos enfocado en la agricultura del período de Desarrollos Regionales e Inca es el que están llevando a cabo Williams y colaboradores (2010) en la región del valle Calchaquí Medio. Ellos utilizan una perspectiva interdisciplinaria que incluye el estudio del paisaje arqueológico en las dimensiones tanto físicas como ideológicas, a partir de las marcas en andenes, caminos, el arte representado en los campos de grabados dispersos entre las tierras agrícolas y asociados a los pucaras, poblados preincas y asentamientos estatales. Este enfoque es integrado por la arqueología, arqueobotánica de microvestigios y pedología, haciendo especial hincapié en la cronología absolu- ta de los espacios agrícolas aterrazados. Por un lado, se observó que la extensión y calidad de la infraestructura agrícola registrada como así también la de regadío mostraban que el área era un importante sector de producción de alimentos, que no se relaciona en tamaño con las áreas residenciales encontradas en los alrededores. Por el otro, parece ser que los principales cultivos fueron los tubérculos, en contraposición a lo que se establece hasta el momento, donde el maíz es considerado el cultivo de mayor importancia en el Noroeste Argentino para épocas precolombinas, aunque señalan que aún es un dato a confirmar.

Al suroeste se encuentra el valle del Bolsón (provincia de Catamarca), en el cual Korstanje (2005, 2007, 2010) ha estudiado las prácticas agrícolas de grupos formativos. En su trabajo redefine el concepto de formativo y establece el de campesinos o aldeanos para estas poblaciones prehispánicas, es decir, lo ve desde una perspectiva social, utilizando argumentos muy significativos para justificar sus ideas. Aunque lo más interesante son los análisis paleobotánicos de las muestras extraídas del suelo junto con los análisis pedológicos de los perfiles excavados en zonas agrícolas (Korstanje y Cuenya 2008). El análisis de los datos obtenidos le permitió distinguir prácticas agrícolas como la fertilización de suelos (guano), rotación y alternancia de cultivos y algunos de los cultígenos que fueron sembrados.

En la región puneña del Noroeste Argentino son tres los trabajos que se destacan en la materia. Olivera y colaboradores (2008) y Tchilinguirian y Olivera (2010) quienes, al igual que nosotras, parten desde una perspectiva geoarqueológica para estudiar las prácticas agrícolas y la conducta social de grupos prehispánicos asentados en la región puneña de Antofagasta de la Sierra (Catamarca), desde el período Formativo hasta el Incaico. Enfocan su trabajo en el manejo del recurso hídrico, por lo tanto estudian los sistemas de regadío, estructuras indispensables para la práctica agrícola en la región, y los cambios climáticos ocurridos durante el Holoceno. Para ello, utilizaron archivos estratigráficos, edáficos, biológicos y geomorfológicos y los proxy datos isotópicos (Olivera et al. 2004). Relacionaron los datos obtenidos con la información arqueológica de las poblaciones prehispánicas y descubrieron que ante la adversidad medioambiental, en vez de abandonar los asentamientos, tendieron a mejorar la 
infraestructura agrícola para contrarrestar las inclemencias climáticas. Esto habría ocurrido durante el período de Desarrollos Regionales continuando hasta la llegada de los incas a la región.

Cerca de Antofagasta de la Sierra se ubican los sitios trabajados por Quesada (2010), específicamente en la región puneña de Antofalla (Catamarca). Al igual que en el caso anterior el aporte hídrico es escaso, por lo tanto las prácticas agrícolas debieron incorporar estructuras de regadío dependiendo totalmente de ellas. Utiliza un enfoque social donde define el paisaje agrario como formas concretas de producción y de puesta en producción del suelo, es decir que el estudio de éste involucra tanto la caracterización de las técnicas de producción como de las relaciones de producción que se generan en torno a ellas. Este planteamiento lo llevó a reconocer la dinámica que el espacio agrícola presentaba, el mismo se expandía y retraía a través del tiempo (desde el período Formativo hasta la actualidad), posiblemente como respuesta a situaciones sociales y condiciones climáticas determinadas.

Al norte, en la Puna jujeña, específicamente en Casabindo, Albeck $(1993,2010)$ estudia los campos agrícolas teniendo en cuenta las relaciones entre el paisaje, el uso del suelo y los patrones de asentamiento. Al igual que en los casos anteriores, el bajo aporte hídrico la lleva a plantear la imposibilidad de la práctica agrícola sin un sistema de regadío, a lo que agrega la necesidad de construir estructuras agrícolas como terrazas o andenes para la contención de los suelos y la preservación de las condiciones necesarias para que las plantas cultivadas puedan desarrollarse. El estudio de esta práctica abarca un amplio espacio temporal que va desde el Formativo hasta los Desarrollos Regionales. Complementariamente Lupo y colaboradores (2010) realizan análisis polínicos en muestras de sedimentos provenientes de algunas estructuras agrícolas, encontrando representadas variedades tanto prehispánicas como hispánicas. Entre las primeras se pueden mencionar cultivos típicos del altiplano como el maíz (Zea mays), quinoa (Chenopodium quinoa), la papa (Solanum tuberosum) y la oca (Oxalis tuberosa).

Como acertadamente plantea Korstanje (2010), no es sencillo desde el punto de vista arqueológico limitar la dinámica de las poblaciones prehispánicas al Noroeste Argentino, ya que los procesos socioculturales registra- dos se extendieron más allá. Sin embargo, por cuestiones de espacio y temática, en este caso acotaremos el estudio al sitio arqueológico tardío de Yasyamayo, ubicado en el valle de Santa María.

La variabilidad medioambiental observada durante el Holoceno en el Noroeste Argentino permitió inferir cual fue el potencial manejo del espacio y de los recursos por parte de las poblaciones prehispánicas. Si bien, en cada región hubo variantes climáticas y cada grupo humano tendió a tomar decisiones adaptativas diferentes frente a iguales condiciones, lo cierto es que las primeras poblaciones agroganaderas aparecen tanto en la Puna Meridional argentina (3000-2500 cal. AP, Olivera et al. 2004), en el valle de Tafí (2300-110o cal. AP, González y Núñez Regueiro 1960; Berberián y Nielsen 1988) y, aparentemente en un sector del piedemonte oriental de Cumbres Calchaquíes dentro del valle de Trancas (3420 $\pm 40 \mathrm{AP}$ ) (Caria et al. 2010), en un momento en el cual las condiciones climáticas tendían a ser más húmedas, y en algunos casos, más cálidas que las actuales.

Si bien en el valle de Santa María no se han efectuado estudios paleoambientales relacionados a los asentamientos prehispánicos conocidos, sí se han realizado estudios sedimentológicos en los márgenes del río Santa María, los que aportaron evidencia que apoya las fluctuaciones climáticas imperantes en los valles Calchaquíes. Strecker (1987) localiza capas de arena ricas en materia orgánica en ambos márgenes del río, las cuales fueron datadas en $2190 \pm 530 \mathrm{AP}$, y que corresponderían a un período de gran humedad para el Holoceno Tardío; para el 800 DC, a partir de estudios pedoestratigráficos de sedimentos ubicados en el margen izquierdo del río, observa condiciones de mayor aridez que las actuales.

Como ya se mencionó, lo que sí se ha estudiado es la geomorfología de la vertiente occidental de Cumbres Calchaquíes (en el piedemonte y ladera oeste), en el valle de Santa María. Se analizó la evolución cuaternaria del paisaje en el área comprendida entre el río Amaicha al sur, el Campo La Hoyada al norte, las divisorias de aguas de Cumbres Calchaquíes al este y el río Santa María al oeste, y cómo esta se relaciona con la ocupación humana prehispánica.

El glacis cubierto es una forma denudativa (Pleistoceno), constituida por tres niveles de formación. El primero y 
más antiguo se encuentra en el límite entre las cumbres y el piedemonte y ha sido fuertemente afectado por procesos morfodinámicos posteriores a su formación, en el que no se observan estructuras arqueológicas. El segundo nivel es el predominante en esta área, y se extiende desde la zona apical del piedemonte hasta la zona media, recubriendo depósitos terciarios. Es la geoforma con la mayor concentración de estructuras arqueológicas (en algunos casos, superpuestas), tanto del período Formativo como de los Desarrollos Regionales. El tercer nivel es cronológicamente el más reciente y se localiza en la parte baja del piedemonte, es más extensivo hacia el sur del área y tiene escasos restos arquitectónicos precolombinos, que generalmente se encuentran cercanos a los glacis cubiertos del segundo nivel (Sampietro y Neder 2011).

La prolongada ocupación puede estar relacionada con la disponibilidad de agua que tienen y han tenido a través del tiempo estas unidades de paisaje; incluso durante el proceso de aridización que la región sufrió durante el Cuaternario, estas geoformas aún contaban con agua gracias al tamaño de sus cuencas imbríferas (Sampietro y Neder 2011).

\section{* Marco conceptual}

La resolución del objetivo planteado se abordó desde la geoarqueología. Esta disciplina provee herramientas muy útiles a la hora de enfrentar los sitios arqueológicos en un sentido amplio y dinámico (Sampietro 2002); se entiende por geoarqueología a la aplicación de las disciplinas y subcampos de las geociencias al estudio del registro arqueológico. El criterio clave es que las interpretaciones arqueológicas se producen usando métodos basados en las geociencias (Rapp y Hill 1998).

Las características de cada unidad de paisaje tienen una importancia evidente para los agricultores, puesto que la pendiente, el relieve y las formas de la textura topográfica imponen patrones de distribución biótica y sedimentológicas. En el paisaje geomorfológico el terreno juega un papel fundamental, a causa de su influencia sobre los regímenes de humedad natural y el equilibrio entre la acumulación de sedimento y la erosión (Butzer 1989), pero la actividad humana también juega un rol importante en la modificación del mismo para la explotación de sus recur- sos, es decir que éste se ve definido por la combinación de procesos tanto culturales como naturales.

Es por ello que se tomó la unidad geomorfológica como área de muestreo debido a que representa una unidad ambiental básica, adecuada para discriminar cualidades y categorías de paisaje; posee génesis y evolución temporal común a toda su superficie y homogeneidad espacial dada por la recurrencia de elementos morfogenéticos endógenos (Sayago y Collantes 1991). Este concepto permite delimitar un área de trabajo en la cual el desarrollo natural de las capas sedimentarias y el paisaje fueron relativamente uniformes, implicando que las alteraciones observadas a microescala serían producto de la actividad humana (Sampietro 2007).

Actualmente sabemos que el accionar humano, tanto pasado como presente, provoca cambios en la composición química y física del suelo y/o sedimento que pueden ser identificados y medidos a través del análisis sedimentológico y geoquímico de algunos de los elementos que lo componen. El impacto que el hombre provoca en las capas sedimentológicas que habita es tal, que las diferencias de concentraciones, asociaciones y distribución espacial de ciertos elementos químicos y características físicas permiten distinguir, claramente, los sedimentos con actividad antrópica.

Las firmas químicas, que son el resultado indirecto de actividades intencionales realizadas de manera recurrente en un lugar dado, presentan, a diferencia de los artefactos arqueológicos, una distribución más regular y constante dentro de un área de ocupación, convirtiéndose en importantes herramientas en el estudio de patrones de uso de tierras prehispánicas. Los elementos o especies químicas que se tienen en cuenta son aquellos que tienden a permanecer prácticamente inalterados, como combinaciones químicas estables, por un prolongado espacio de tiempo en el sedimento. Para ello, como primera medida es necesario conocer la dinámica del paisaje en la cual se asienta el sitio arqueológico, para luego poder interpretar sus contextos culturales (Roldán et al. 2008).

En este trabajo, es necesario distinguir entre suelo y capa de sedimento, debido a que en el sitio de Yasyamayo el suelo natural no existe, lo que observamos son capas sedimentarias que se depositaron a través del tiempo como 
resultado de diferentes fenómenos naturales, y sobre las cuales se asentaron poblaciones prehispánicas. Las capas sedimentarias responden a la ley de superposición, son depositadas una sobre otra, donde la capa inferior es anterior a la superior; mientras que los horizontes de un suelo, si bien pueden ser identificados como capas en un perfil, son sincrónicos e interdependientes yen general se desarrollan de arriba hacia abajo y necesitan de tiempos diferentes para su formación (Van Breemen y Buurman 2003). Por lo tanto, los análisis físicos y químicos que se practican en un suelo con evidencia de actividad antrópica son interpretados de una forma conjunta y distinta a los realizados a un perfil formado por capas de sedimentos con evidencia de actividad humana pasada.

Ahora bien, se considera fundamental definir qué tipo de estructuras agrícolas fueron registradas. En la arqueología del Noroeste Argentino es común encontrar que términos como terraza y andén de cultivo son utilizados como sinónimos, cuando en realidad no lo son. Una de las características más destacables, que diferencia una terraza de un andén es la actividad intencional de relleno que se implementa en los andenes, para nivelar y aumentar la cantidad de sedimento dentro de estas estructuras (Williams et al. 2010), hecho que no ocurre en las terrazas; éstas son construidas y con el tiempo y de forma natural se nivelan y rellenan con sedimento que es arrastrado por el agua, viento o la gravedad (Denevan 1980). En este caso en particular estamos frente a terrazas de cultivo.

\section{* Metodología}

Una vez realizada la revisión bibliográfica, se decidió prospectar la zona del glacis cubierto nivel 2 ubicado en la región de Yasyamayo. En él se encontraron estructuras arqueológicas, por lo que se decidió excavar cinco calicatas, tres en la zona distal y dos en la zona media, mientras que la zona apical no pudo muestrearse debido a su inaccesibilidad.

Tres de los cinco perfiles, Y-P1 (perfil testigo), Y-P2 (estructura circular) e Y-P3 (estructura agrícola) fueron excavados en la zona distal de la unidad de paisaje, los otros dos perfiles agrícolas, Y-P4 e Y-P5, en la zona media. Cada calicata medía aproximadamente $1 \mathrm{~m}$ de ancho $\mathrm{x} 1 \mathrm{~m}$ de largo x $0.6 \mathrm{~m}$ de profundidad, medidas que variaron dependiendo de como se presentaba el terreno en cada caso.

Se realizaron las descripciones de campo siguiendo las normas de Etchevere (1976), se identificaron las capas que componían cada perfil cuando se pudieron diferenciar, muestreando el sector medio de las mismas, en caso contrario se tomaron muestras sistemáticamente cada $10 \mathrm{~cm}$. Se determinaron textura, color y $\mathrm{pH}$ de acuerdo a las técnicas propuestas por Cuenya y Puchulu (2000), porcentaje de materia orgánica según Walkley y Black (1934), fósforo orgánico y fósforo disponible, adaptados de Fiske y Subbarow (1925), y calcio, hierro disponible, manganeso disponible y cobre disponible adaptados del manual de la Federal Agricultural Office (Dewis y Freitas 1984), y modificadas para su aplicación en las muestras arqueológicas (Roldán et al. 2005).

\section{* Resultados}

En la zona distal y media de esta unidad de paisaje, se encontraron terrazas agrícolas y una estructura circular simpe asociada a ellas (ver Figuras 3 y 4 ); en la zona apical se desconoce la existencia de estructuras prehispánicas.

En todos los perfiles antrópicos analizados pudo establecerse la superficie de ocupación a partir de los diferentes indicadores físicos y químicos considerados (Tablas 1 y 2). En general, este nivel se encuentra entre los 10 y 40 $\mathrm{cm}$ de profundidad, enterrado bajo una o dos capas de sedimento. En el caso de la estructura circular Y-P2 en la capa 3 se observa laminación horizontal, acompañada de textura fina (franco arcillosa) y coloración diferente $(2.5 \mathrm{Y}$ $6 / 3$ ) a la de las otras capas que conforman el perfil, todo lo cual sugiere que éste fue el nivel de ocupación (Figuras 5; ver también Figura 3).

En Y-P3 (estructura agrícola) la presencia de estructuras en bloques subangulares y un valor de fósforo orgánico que denota una pequeña elevación en su concentración con respecto a las capas sub y suprayacentes son evidencia de que la capa 3 fue la superficie de cultivo (Figura 6; ver también Figura 3).

En el caso de Y-P4 (estructura agrícola), la coloración (2.5Y 7/1) y textura (franco arcillo arenosa) diferentes a 


\begin{tabular}{|c|c|c|c|c|c|c|c|c|c|c|c|c|c|c|}
\hline \multirow{2}{*}{\multicolumn{2}{|c|}{ Muestra }} & \multirow{3}{*}{$\begin{array}{c}\begin{array}{c}\text { Prof. } \\
\text { cm }\end{array} \\
0-10\end{array}$} & \multirow{3}{*}{$\begin{array}{l}\mathrm{pH} \\
8.4\end{array}$} & \multirow{3}{*}{$\begin{array}{c}\begin{array}{c}\text { Textura y } \\
\text { estructura }\end{array} \\
\begin{array}{c}\text { Franco arcillo } \\
\text { limosa }\end{array} \\
\end{array}$} & \multicolumn{2}{|c|}{ Color } & \multirow{2}{*}{$\begin{array}{l}\text { Clasifica- } \\
\text { ción de la } \\
\text { materia } \\
\text { orgánica }\end{array}$} & \multirow{2}{*}{$\begin{array}{l}\text { Calidad } \\
\text { de la } \\
\text { materia } \\
\text { orgánica }\end{array}$} & \multirow{2}{*}{$\begin{array}{l}\text { Calcio } \\
\text { ppm }\end{array}$} & \multirow{2}{*}{$\begin{array}{c}\text { Fósforo } \\
\text { disp. } \\
\text { ppm }\end{array}$} & \multirow{2}{*}{$\begin{array}{c}\text { Fósforo } \\
\text { orgánico } \\
\text { ppm }\end{array}$} & \multirow{2}{*}{$\begin{array}{c}\text { Fe } \\
\text { disp. } \\
\text { ppm }\end{array}$} & \multirow{2}{*}{$\begin{array}{l}\text { Mn } \\
\text { disp. } \\
\text { ppm }\end{array}$} & \multirow{2}{*}{$\begin{array}{l}\mathrm{Cu} \\
\text { disp } \\
\text { ppm }\end{array}$} \\
\hline & & & & & Seco & Húmedo & & & & & & & & \\
\hline \multirow{6}{*}{ Y-P1 } & $\mathrm{Cl}_{1}$ & & & & $2.5 \mathrm{Y} 6 / 3$ & $2.5 \mathrm{Y}_{4} / 4$ & $\begin{array}{l}\text { Extremada- } \\
\text { mente pobre }\end{array}$ & Buena & $3.976 \times 10^{6}$ & 159 & 54 & 5.7 & 0.02 & 0.6 \\
\hline & $\mathrm{C}_{2}$ & $10-20$ & 8.6 & $\begin{array}{c}\text { Franco arcillo } \\
\text { limosa }\end{array}$ & $2.5 \mathrm{Y} 6 / 2$ & $2.5 \mathrm{Y}_{4} / 4$ & $\begin{array}{l}\text { Moderada- } \\
\text { mente pobre }\end{array}$ & Buena & $15.407 \times 10^{6}$ & 149 & 205 & 4.7 & 0.02 & 0.8 \\
\hline & $\mathrm{C}_{3}$ & $20-30$ & 8.9 & $\begin{array}{c}\text { Franco arcillo } \\
\text { limosa }\end{array}$ & $2.5 \mathrm{Y} \mathrm{6/2}$ & $2.5 \mathrm{Y}_{4} / 4$ & Pobre & Buena & $22.188 \times 10^{6}$ & 122 & 521 & 6.5 & 0.01 & 0.2 \\
\hline & $\mathrm{C}_{4}$ & $30-40$ & 8.7 & Franco limosa & $2.5 \mathrm{Y} 7 / 3$ & $2.5 \mathrm{Y}_{4} / 4$ & Pobre & Buena & $21.162 \times 10^{6}$ & 116 & 39 & 3.7 & 0.01 & 0.6 \\
\hline & $\mathrm{C}_{5}$ & $40-50$ & 8.9 & $\begin{array}{c}\text { Franco arcillo } \\
\text { limosa }\end{array}$ & $2.5 \mathrm{Y} 7 / 3$ & $2.5 \mathrm{Y}_{4 / 3}$ & Pobre & Buena & $32.833 \times 10^{6}$ & 129 & 273 & 1.8 & o & 0.8 \\
\hline & C6 & $50-60$ & 9 & Franco limosa & $2.5 \mathrm{Y} 7 / 3$ & $2.5 \mathrm{Y}_{4} / 3$ & Pobre & Buena & $25.908 \times 10^{6}$ & 130 & 69 & 4.5 & 0.03 & 0.6 \\
\hline \multirow{4}{*}{ Y-P2 } & $\mathrm{Cl}_{1}$ & $0-10$ & 8.7 & $\begin{array}{c}\text { Franco arcillo } \\
\text { limosa }\end{array}$ & $2.5 \mathrm{Y} \mathrm{6/3}$ & $2.5 \mathrm{Y}_{3} / 3$ & Pobre & Buena & $9.234 \times 10^{6}$ & 143 & 375 & 0.9 & o & 0.6 \\
\hline & $\mathrm{C}_{2}$ & $10-20$ & 8.7 & $\begin{array}{c}\text { Franco arcillo } \\
\text { limosa }\end{array}$ & $2.5 \mathrm{Y} \mathrm{6/2}$ & $2.5 \mathrm{Y}_{3} / 3$ & $\begin{array}{l}\text { Moderada- } \\
\text { mente pobre }\end{array}$ & Buena & $14.172 \times 10^{6}$ & 170 & 531 & o & 0.05 & 0.8 \\
\hline & $\mathrm{C}_{3}$ & $20-30$ & 8.9 & $\begin{array}{c}\text { Franco arci- } \\
\text { llosa } \\
\text { Laminar }\end{array}$ & $2.5 \mathrm{Y} 6 / 3$ & $2.5 \mathrm{Y}_{3} / 2$ & Pobre & Buena & $12.264 \times 10^{6}$ & 167 & 520 & o & 0.01 & 0.8 \\
\hline & $\mathrm{C}_{4}$ & $30-40$ & 8.6 & Franco limosa & $2.5 \mathrm{Y} \mathrm{6/2}$ & $2.5 \mathrm{Y}_{3} / 3$ & Pobre & Buena & $19.779 \times 10^{6}$ & 211 & 628 & $7 \cdot 3$ & 0.01 & 1.1 \\
\hline \multirow{6}{*}{$\mathrm{Y}-\mathrm{P}_{3}$} & $\mathrm{C}_{1}$ & $0-5$ & $7 \cdot 4$ & $\begin{array}{c}\text { Franco arcillo } \\
\text { limosa }\end{array}$ & $2.5 \mathrm{Y} 6 / 4$ & $2.5 \mathrm{Y}_{4} / 4$ & Rica & Buena & $3.174 \times 10^{6}$ & 139 & 340 & 32.1 & 0.7 & 0.8 \\
\hline & $\mathrm{C}_{2}$ & $5-14$ & 8.6 & $\begin{array}{c}\text { Franco arcillo } \\
\text { limosa }\end{array}$ & $2.5 \mathrm{Y} \mathrm{6/4}$ & $2.5 \mathrm{Y}_{3} / 2$ & Pobre & Buena & $3.407 \times 10^{6}$ & 131 & 40 & 0.9 & 0.03 & 0.6 \\
\hline & $\mathrm{C}_{3}$ & $14-24$ & 8.7 & $\begin{array}{c}\text { Franco arcillo } \\
\text { limosa } \\
\text { Bloques } \\
\text { subangulares }\end{array}$ & $2.5 \mathrm{Y} 6 / 4$ & $2.5 \mathrm{Y}_{3} / 3$ & Pobre & Buena & $5.555 \times 10^{6}$ & 124 & 210 & 2.7 & 0.02 & 0.6 \\
\hline & $\mathrm{C}_{4}$ & $24-32$ & 8.7 & $\begin{array}{c}\text { Franco arcillo } \\
\text { limosa }\end{array}$ & $2.5 \mathrm{Y} \mathrm{6/4}$ & $2.5 \mathrm{Y}_{3} / 3$ & Pobre & Buena & $5.771 \times 10^{6}$ & 138 & 109 & 2.8 & 0.02 & 0.6 \\
\hline & $\mathrm{C}_{5}$ & $32-40$ & 8.7 & Franco limosa & $2.5 \mathrm{Y} \mathrm{6/3}$ & $2.5 \mathrm{Y}_{4 / 4}$ & Pobre & Buena & $17.571 \times 10^{6}$ & 135 & 25 & 0.9 & 0.03 & 0.6 \\
\hline & $\mathrm{C} 6$ & $40-50$ & 8.7 & Franco limosa & $2.5 \mathrm{Y} 6 / 3$ & $2.5 \mathrm{Y}_{4} / 4$ & Pobre & Buena & $30.91 \times 10^{6}$ & 150 & 302 & 3.7 & 0.02 & 0.02 \\
\hline \multirow{5}{*}{$\mathrm{Y}-\mathrm{P}_{4}$} & $\mathrm{Cl}_{1}$ & $0-8$ & 6 & $\begin{array}{c}\text { Franco arcillo } \\
\text { limosa }\end{array}$ & $2.5 Y_{5} / 3$ & $2.5 \mathrm{Y}_{3 / 2}$ & Rica & Buena & $4.361 \times 10^{6}$ & 150 & 543 & 19.6 & 0.26 & 0.6 \\
\hline & $\mathrm{C}_{2}$ & $8-25$ & 7.5 & Franco limosa & $2.5 \mathrm{Y} 6 / 2$ & $2.5 \mathrm{Y}_{3} / 3$ & $\begin{array}{l}\text { Extremada- } \\
\text { mente pobre }\end{array}$ & Buena & $0.926 \times 10^{6}$ & 180 & 509 & 1.9 & 0.06 & 4 \\
\hline & $\mathrm{C}_{3}$ & $25-32$ & 8.6 & $\begin{array}{c}\text { Franco arcillo } \\
\text { limosa }\end{array}$ & $2.5 Y_{7} / 1$ & $2.5 \mathrm{Y} 2,5 / 1$ & $\begin{array}{l}\text { Extremada- } \\
\text { mente pobre }\end{array}$ & $\begin{array}{c}\text { Muy } \\
\text { buena }\end{array}$ & $2.693 \times 10^{6}$ & 164 & 802 & 4.8 & 0.01 & o \\
\hline & $\mathrm{C}_{4}$ & $32-52$ & 9.1 & Franco limosa & $2.5 \mathrm{Y} \mathrm{6/2}$ & $2.5 \mathrm{Y}_{3} / 2$ & - & - & $2.589 \times 10^{6}$ & 166 & 343 & 1.9 & 0.07 & 0.6 \\
\hline & $\mathrm{C}_{5}$ & $52-64$ & 9.1 & Limosa & $2.5 \mathrm{Y} 6 / 3$ & $2.5 \mathrm{Y}_{3} / 3$ & $\begin{array}{l}\text { Extremada- } \\
\text { mente pobre }\end{array}$ & $\begin{array}{c}\text { Muy } \\
\text { buena }\end{array}$ & $1.771 \times 10^{6}$ & 157 & 366 & 4.8 & 0.08 & 0.6 \\
\hline \multirow{4}{*}{ Y-P5 } & $\mathrm{C}_{1}$ & $0-10$ & 8 & $\begin{array}{c}\text { Franco arcillo } \\
\text { limosa }\end{array}$ & $2.5 Y_{5} / 2$ & $2.5 \mathrm{Y}_{3} / 2$ & $\begin{array}{l}\text { Moderada- } \\
\text { mente pobre }\end{array}$ & Buena & $5.178 \times 10^{6}$ & 149 & 342 & 12.8 & 0.03 & o \\
\hline & $\mathrm{C}_{2}$ & $10-20$ & 6.7 & Franco limosa & $2.5 \mathrm{Y}_{4 / 2}$ & $2.5 \mathrm{Y} 2,5 / 1$ & $\begin{array}{l}\text { Extremada- } \\
\text { mente rica }\end{array}$ & Buena & $7.495 \times 10^{6}$ & 155 & 405 & 19.6 & 0.06 & 0.4 \\
\hline & $\mathrm{C}_{3}$ & $20-30$ & 8.1 & $\begin{array}{c}\text { Franco arcillo } \\
\text { limosa }\end{array}$ & $2.5 Y_{5} / 2$ & $2.5 \mathrm{Y}_{3} / 2$ & Pobre & Buena & $5.555 \times 10^{6}$ & 166 & 248 & o & 0.07 & o \\
\hline & $\mathrm{C}_{4}$ & $30-40$ & 8.2 & $\begin{array}{c}\text { Franco arcillo } \\
\text { limosa }\end{array}$ & $2.5 Y_{5} / 2$ & $2.5 \mathrm{Y}_{3} / 2$ & Pobre & Buena & $5.587 \times 10^{6}$ & 142 & 296 & 2.8 & 0.07 & 0.4 \\
\hline
\end{tabular}

Tabla 1. Resultados de los análisis geobioquímicos realizados a los perfiles Y-P1, Y-P2, Y-P3, Y-P4 e Y-P5. 


\begin{tabular}{|c|c|c|}
\hline Perfil & Funcionalidad & Descripción \\
\hline Y-P1 & $\begin{array}{l}\text { Perfil testigo, utilizado para conocer la dinámica natural de la } \\
\text { unidad de paisaje (zona distal de la geoforma). }\end{array}$ & $\begin{array}{l}\text { La superficie natural contemporánea a la superficie de ocupación pudo definir- } \\
\text { se en la capa } 3 \text { a los } 20 \mathrm{~cm} \text { de profundidad gracias a una elevada concentración } \\
\text { de fósforo orgánico, un leve aumento en la concentración de Fe disponible y } \\
\text { disminución del Cu disponible. }\end{array}$ \\
\hline $\mathrm{Y}-\mathrm{P2}_{2}$ & $\begin{array}{l}\text { Estructura circular simple, forma parte de la infraestructura } \\
\text { agrícola prehispánica en los valles del Noroeste Argentino. } \\
\text { Lugar de descanso y/o resguardo de herramientas agrícolas } \\
\text { (zona distal de la geoforma). }\end{array}$ & $\begin{array}{l}\text { La superficie ocupacional se presenta a los } 20 \mathrm{~cm} \text { de profundidad en la capa } 3 \text {; } \\
\text { ésta fue determinada a partir de la existencia de una laminación horizontal, } \\
\text { textura más fina, coloración diferente, ausencia de hierro disponible y presen- } \\
\text { cia de raíces. }\end{array}$ \\
\hline $\mathrm{Y}-\mathrm{P}_{3}$ & $\begin{array}{l}\text { Estructura agrícola o terraza de cultivo, utilizada para el culti- } \\
\text { vo de diferentes vegetales (zona distal de la geoforma). }\end{array}$ & $\begin{array}{l}\text { La superficie de cultivo se presenta a los } 14 \mathrm{~cm} \text { de profundidad en la capa } 3 \text { y es } \\
\text { definida por la existencia de estructuras en bloques subangulares (edafización } \\
\text { incipiente) y elevada concentración de fósforo orgánico (abono orgánico). }\end{array}$ \\
\hline $\mathrm{Y}-\mathrm{P}_{4}$ & $\begin{array}{l}\text { Estructura agrícola o terraza de cultivo, utilizada para el culti- } \\
\text { vo de diferentes vegetales (zona media de la geoforma). }\end{array}$ & $\begin{array}{l}\text { La superficie de cultivo se presenta a los } 25 \mathrm{~cm} \text { de profundidad en la capa } 3 \text {, de- } \\
\text { finida por una coloración y textura diferente, elevada concentración de fósforo } \\
\text { orgánico (abono orgánico) y buena calidad de la materia orgánica. }\end{array}$ \\
\hline Y-P5 & $\begin{array}{l}\text { Estructura agrícola o terraza de cultivo, utilizada para el culti- } \\
\text { vo de diferentes vegetales (zona media de la geoforma). }\end{array}$ & $\begin{array}{l}\text { La superficie de cultivo se presenta a los } 10 \mathrm{~cm} \text { de profundidad en la capa } 2 \text {, } \\
\text { definida por un color y textura diferentes, } \mathrm{pH} \text { ácido, concentración de fósforo } \\
\text { orgánico elevado (abono orgánico), materia orgánica extremadamente rica e } \\
\text { importantes concentraciones de calcio, hierro y manganeso disponibles. }\end{array}$ \\
\hline
\end{tabular}

Tabla 2. Síntesis de cada perfil analizado, donde se realiza una breve descripción de los mismos en relación a la funcionalidad de las estructuras dentro de las cuales se los excavó y de la geoquímica del sedimento.

la de las otras capas, una importante concentración de fósforo orgánico, bastante más elevada que la observada en las capas supra y subyacentes, sumada a la muy buena calidad de la materia orgánica, hacen de la capa 3 la superficie de cultivo (ver Figuras 4 y 6 ).

Mientras que en Y-P5, el color (2.5Y 4/2) y textura (franco limosa) son distintos a las otras capas, el pH ácido, concentración de fósforo orgánico elevado, materia orgánica extremadamente rica y concentraciones de calcio, hierro y manganeso disponibles destacables definen a la capa 2 como la superficie de cultivo (ver Figuras 4 y 6).

En el perfil testigo Y-Pr pudo establecerse la superficie natural contemporánea a la superficie de ocupación prehispánica registrada para los otros perfiles. La misma está definida por una elevada concentración de fósforo orgánico, un leve aumento en la concentración de hierro disponible y la disminución del cobre disponible observables en la capa 3 (ver Figura 3).

En general, el comportamiento de los diferentes indicadores geoquímicos medidos en todos los perfiles muestra diferencias establecidas por el tipo de actividad antrópica desarrollada en cada lugar; de esta forma, las características observadas en el perfil de la estructura circular Y-P2 (ver Figura 5) son evidentemente diferentes a las observadas en las terrazas agrícolas $\mathrm{Y}_{-} \mathrm{P}_{3}, \mathrm{Y}-\mathrm{P}_{4} \mathrm{e}$ Y-P5 (ver Figura 6).

Para finalizar, también se registra una marcada diferencia entre las áreas donde el hombre interactuó con la naturaleza y aquellas que no fueron alteradas por éste, situación observable al comparar los resultados obtenidos para los perfiles antrópicos Y-P2, Y-P3, Y-P4 e Y-P5 y los obtenidos para el perfil testigo Y-P1.

\section{* Discusión}

No es frecuente encontrar trabajos de investigación referentes a estudios físicos y geoquímicos de capas de tierras agrícolas no edafizadas. Por lo general, las poblaciones prehispánicas tendían a asentarse en paisajes estables, es decir sobre un suelo (Butzer 1989) y no sobre estratos sedimentarios. Sin embargo, en esta región las condiciones 




Figura 5. Y-P2, estructura circular simple. Glacis cubierto nivel 2 Yasyamayo, valle de Santa María, Tucumán, Argentina.

climáticas no llegaron a ser lo suficientemente benignas y/o mantenerse estables el tiempo necesario como para que un suelo pudiera desarrollarse. Como consecuencia de ello, los perfiles estudiados están formados por un conjunto de capas sedimentológicas. Por lo tanto, el tratamiento del mismo, como así también la interpretación de los resultados obtenidos, no será igual a la que se realiza ante la presencia de un suelo.

El nivel de ocupación prehispánico en los perfiles antrópicos se halló entre los 10 y $40 \mathrm{~cm}$ de profundidad, enterrado bajo una o dos capas de sedimento. La presencia de 


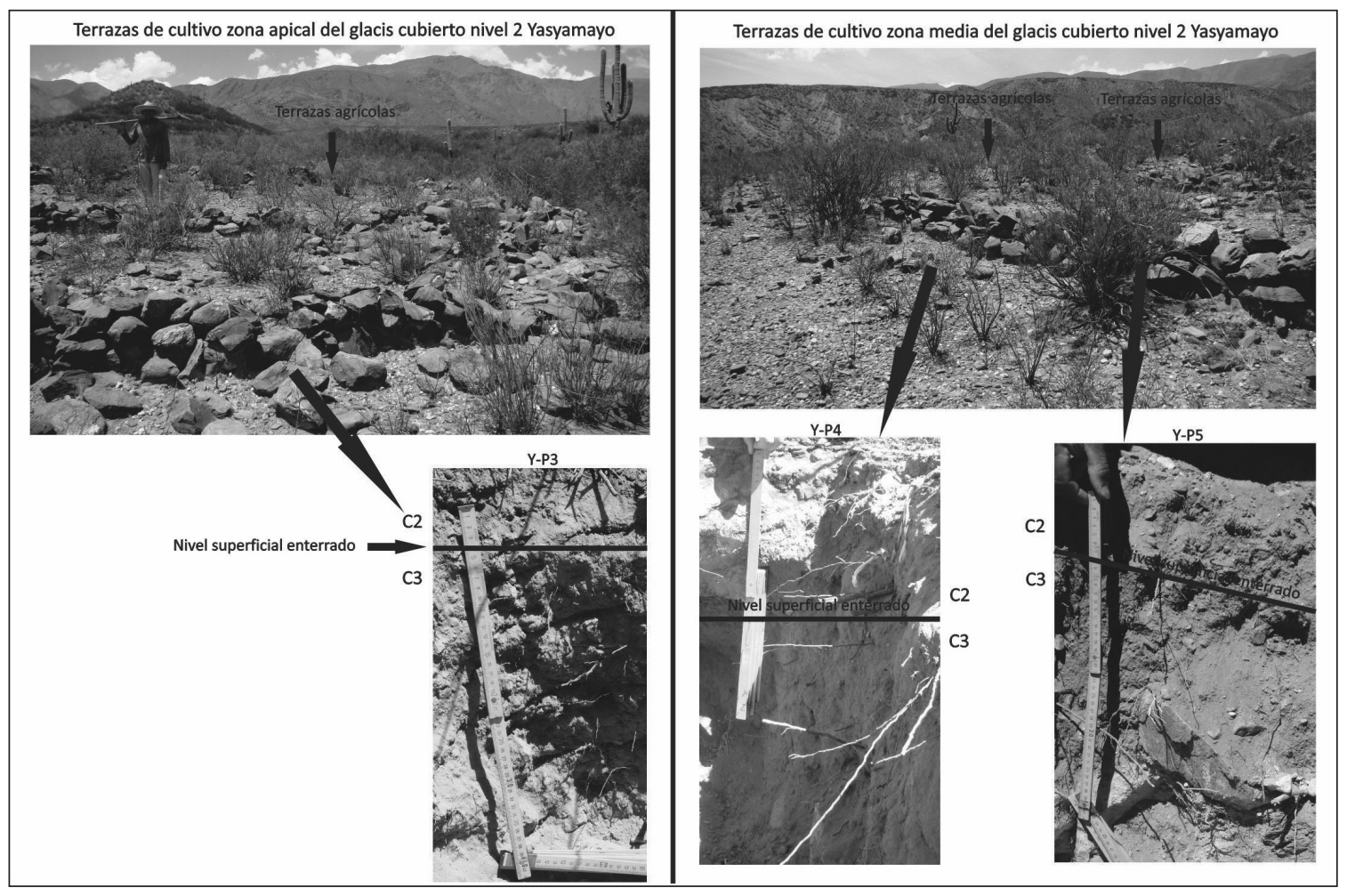

Figura 6. Terrazas de cultivo. Glacis cubierto nivel 2 Yasyamayo, valle de Santa María, Tucumán, Argentina.

estructuras, diferencias en la textura, el color y el $\mathrm{pH}$, concentraciones elevadas de fósforo orgánico, la calidad de la materia orgánica y diferencias en las concentraciones de calcio y micronutrientes son los indicadores geoquímicos de dicho nivel (ver Tabla 2). En ninguno de estos perfiles se hallaron restos arqueológicos, probablemente como resultado del tipo de actividad practicada. Sin embargo, Sampietro y Neder (2011) encuentran en las inmediaciones del sitio, fragmentos cerámicos de tipo santamariano. Sumado a ello, en otro glacis cubierto de nivel 2 hallan no solo material cerámico característico del Desarrollo Regional, sino también patrones de asentamiento propios de este período que se superponen a otros formativos. Esta evidencia les permite argumentar que estas geoformas pudieron ser explotadas a lo largo del tiempo por diferentes grupos humanos, a pesar de las variaciones climáticas que afectaron al valle, probablemente gracias a su permanente disponibilidad de agua. Este razonamiento se ve reforzado por el trabajo de investigación que Rivolta lleva a cabo en los sitios Formativo y Tardío, Los Cardones (Rivolta 2007, 2010; Rivolta y Salazar 2007), ubica- dos también sobre un glacis cubierto de nivel 2, hallados superpuestos, y donde el asentamiento Tardío es definido como un conglomerado semiurbano que fue ocupado hasta la época del contacto (Rivolta 2007).

Entonces, a pesar de no haber hallado en el sitio de Yasyamayo, estructuras residenciales que puedan confirmar la cronología tardía relativa, la evidencia presentada más arriba es suficiente, por el momento, como para establecer su adscripción al período de Desarrollos Regionales. Lo cual no quita la posibilidad de que, en realidad, las estructuras agrícolas hayan sido originalmente construidas y utilizadas por grupos formativos, lo que en parte está evidenciado por una estructura circular simple asociada a las terrazas de cultivo, relación común en los campos agrícolas de grupos formativos (Sampietro 2002), y a la superposición de asentamientos formativos y tardío como los hallados en otros glacis cubiertos de nivel 2.

En el perfil Y-P3, excavado dentro de una terraza agrícola (ver Figuras 3 y 6), la superficie de ocupación $\left(C_{3}\right)$ se 
presenta con estructura en bloques subangulares, lo cual indica que en algún momento estas terrazas fueron irrigadas o al menos concentraron humedad. El agua es una de las propiedades más importantes para el desarrollo de un suelo, sin ella no existiría la pedogénesis (Rapp y Hill 1998), es decir, que un nivel con edafización incipiente de origen antrópico comenzó a desarrollarse en una capa de sedimento, todo ello respaldado por la presencia del parapeto de contención de la terraza de cultivo que retuvo la humedad y el sedimento. Debido a las condiciones imperantes, incluso en la actualidad, una vez abandonadas estas estructuras el nivel en cuestión fue enterrado. Cuando un suelo comienza a formarse lo primero en diferenciarse del material parental es el horizonte A, luego el B y así sucesivamente (Rapp y Hill 1998), es muy posible que, una vez abandonadas las terrazas, los procesos edáficos se vieran limitados dejando reminiscencias de un horizonte pobremente edafizado $\left(\mathrm{C}_{3}\right)$ que fue posteriormente sepultado.

Todo ello no hubiese sido posible sin riego. Evidentemente las condiciones climáticas en el valle fueron siempre áridas, con algunas fluctuaciones, por lo que la práctica agrícola indefectiblemente necesitaba un aporte hídrico externo, situación observable en las acequias asociadas a las terrazas estudiadas en Yasyamayo. Si bien se han encontrado estructuras agrícolas a 4000 m.snm en la zona de Casabindo (Albeck 2010), lo cierto es que para que los cultivos sean exitosos deben darse cuatro factores: 1) la composición química de los sedimentos o suelos debe ser apropiada para el desarrollo de las plantas cultivadas; 2 ) debe existir una concentración justa de humedad; 3) las temperaturas tienen que ser apropiadas para cada cultivo; y 4) debe construirse una infraestructura agrícola que permita mantener y potenciar los factores ya mencionados.

La concentración de fósforo orgánico en las superficies de cultivo de las estructuras agrícolas se registra un poco (Y-P3) o bastante más elevada (Y-P4 e Y-P5) que las capas subyacentes (ver Tabla 1). Esta situación puede estar indicando la utilización de fertilizantes orgánicos para el mantenimiento de las tierras de cultivo, práctica que ya ha sido descrita por Korstanje (2005) en terrazas agrícolas formativas encontradas en el valle del Bolsón (Catamarca), donde como abono se utilizó guano; y por Roldán y colaboradores (2008) en terrazas agrícolas formativas del valle de Tafí, a partir de evidencia geoquímica. Por el momento, no nos es posible contrastar los resultados con datos históricos o etnográficos de la región ya que el único trabajo de este tipo está en sus comienzos (Álvaro Codormí, com. pers. 2013).

Queda claro que las condiciones geoquímicas en las que se cultivó no eran para nada favorables, sin embargo, este paisaje fue explotado por poblaciones agrícolas durante un largo lapso (períodos Formativo y Desarrollos Regionales) y bajo condiciones climáticas fluctuantes, por lo que no es errado decir que aun en tierras y condiciones climáticas desfavorables pueden crecer determinados tipos de cultivos. Probablemente el producto que se obtuvo de esta actividad no fue el mejor, pero sí lo suficientemente abundante como para sostener la población asentada en el piedemonte. Ejemplos de esta misma situación se registran en los sitios agrícolas prehispánicos de la Puna, como Antofagasta de la Sierra, donde para contrarrestar las inclemencias climáticas se mejora la infraestructura agrícola (Tchilinguirian y Olivera 2010), o Antofalla, donde a través del tiempo y como respuesta a condicionantes sociales y climáticas el espacio agrícola se expandía y retraía, o como el caso extremo de andenes construidos sobre afloramientos rocosos que Albeck (2010) registra en Casabindo, en la Puna de Jujuy.

Algunos investigadores como Berberián y Nielsen (1988) sugieren que las estructuras circulares simples ubicadas dentro de campos de cultivo, similares a la estructura circular donde se excavó el perfil Y-P2 (ver Figuras 3 y 5), tuvieron como función almacenar alimentos. Sin embargo, la laminación que ésta presenta en la superficie ocupacional junto con el cambio de textura más fina, la ausencia de hierro disponible y la presencia de raíces son más bien indicativos de un piso antes que del fondo de una estructura de almacenamiento, por lo que posiblemente fueron utilizados como lugar de descanso y/o resguardo de agricultores y herramientas agrícolas.

\section{$*$ Conclusiones}

Contrario a lo que uno podría pensar, a condiciones climáticas adversas este pueblo precolombino respondió con un mayor cuidado de las tierras de cultivo, siendo el abono 
una de las prácticas utilizadas. Ello no significó necesariamente un óptimo rendimiento, pero sí lo suficientemente adecuado como para poder obtener alimentos.

La construcción de una infraestructura agrícola junto con la utilización de abono orgánico, provocaron cambios radicales, sutiles pero importantes, en las características de las tierras de cultivo, llegando a identificarse procesos edáficos incipientes producto de la atención y cuidado implementados por el hombre.

En síntesis, la región ha sido lugar de asentamiento humano durante un importante lapso temporal, que ha albergado poblaciones cazadoras recolectoras, formativas y tardías (Desarrollos Regionales, Inca e Hispanoindígena). Los grupos formativos muestran una fuerte influencia de las poblaciones asentadas en el valle vecino de Tafí, al punto de que algunos investigadores creen que estos sitios fueron ocupados por ellas. Por motivos que aún desconocemos, pero que coinciden con importantes cambios climáticos, estas comunidades abandonan sus asentamientos, los que posteriormente son reutilizados por grupos tardíos conocidos como Santa María. Ellos deben adaptarse a condiciones climáticas muy áridas y frías, y para ello modifican la infraestructura agrícola, utilizan otras técnicas como el abono y seleccionan los lugares más propicios para sus cultivos, como las unidades de paisaje (glacis cubierto de nivel 2) que aún poseen agua.

Agradecimientos Agradecemos al Dr. Rodolfo Soberón y a la Dra. Melina Sgariglia por su ayuda en los trabajos de laboratorio. Al Consejo de Investigaciones de la Universidad Nacional de Tucumán (CIUNT), al Consejo Nacional de Investigaciones Científicas y Técnicas (CONICET) y la Agencia Nacional de Investigaciones Científicas y Técnicas (ANPCyT), por el subsidio a los diferentes proyectos que permitieron la realización de este trabajo.

\section{* Referencias citadas}

ALBECK, M. E., 1993. Contribución al estudio de los sistemas agrícolas prehispánicos de Casabindo (Puna de Jujuy). Tesis Doctoral. Universidad Nacional de La Plata, La Plata.

2010. La vida agraria en los Andes del sur. En Nueva Historia argentina. Los Pueblos originarios y la Conquista, M. Tarragó, (Ed.), pp. 187-228. Editorial Sudamericana, Buenos Aires.

ARREGUEZ, G. y L. GONZÁLEZ, 2007. Arqueobotánica de Cueva de los Corrales 1: Un sitio de altura. Primeras Jornadas de Jóvenes Investigadores UNT-AUGM. Consejo de Investigaciones de la Universidad Nacional de Tucumán, San Miguel de Tucumán.

ASCHERO, C. y E. RIBOTTA, 2007. Usos del espacio, tiempo y funebria en El Remate (Los Zazos, Amaicha del Valle, Tucumán). En Paisajes y procesos sociales en Tafídel Valle, P. Arenas, B. Manasse y E. Noli (Eds.), pp. 79-94. San Miguel de Tucumán.

BERBERIÁN, E. y A. NIELSEN, 1988. Sistemas de asentamiento prehispánicos en la etapa formativa del valle de Tafí. En Sistemas de asentamiento prehispánico en el valle de Tafí, E. Berberián y A. Nielsen (Eds.), pp. 21-51. Comechingonia, Córdoba.

BUTZER, K., 1989. Arqueología un ecología del hombre. Ediciones Bellaterra, Madrid.
CABRERA, A., 1976. Enciclopedia argentina de agricultura y jardinería. Editorial ACME, Buenos Aires.

CARIA, M. A., J. MARTÍNEZ y N. OLISZEWSKY, 2006. Geomorfología y arqueología de la quebrada del río de los Corrales (Infiernillo-Tafí del Valle-Tucumán-Argentina). III Congreso Argentino de Cuaternario y Geomorfología, vol. 1, pp. 145-154. Córdoba.

CARIA, M. A., M. M. SAMPIETRO y J. SAYAGO, 2010. Las sociedades aldeanas y los cambios climáticos. XIV Congreso Nacional de Arqueología Argentina, vol. 2, pp. 217-224. Rosario.

CUENYA, P. y M. E. PUCHULU, 2000. Cuadernillo: Guía de trabajos prácticos. Facultad de Ciencias Naturales e Instituto Miguel Lillo, Universidad Nacional de Tucumán, San Miguel de Tucumán.

DEMARRAIS, E., 2001. La arqueología del norte del Valle Calchaquí. En Historia argentina prehispánica, E. Berberián y A. Nielsen (Eds.), pp. 289-346. Ediciones Brujas, Córdoba.

DENEVAN, W., 1980. Tipología de configuraciones agrícolas prehispánicas. América Indígena XL (4): 619-652.

DEWIS, J. y F. FREITAS, 1984. Métodos físicos y químicos de análisis de suelos y aguas. Boletín de suelos de la FAO 10. 
ETCHEVERE, P., 1976. Normas de reconocimiento de suelos. Secretaría de Estado de Agricultura y Ganadería de la Nación, Buenos Aires.

FISKE, G. e Y. SUBBAROW, 1925. The colorimetric determination of phosphorous. The Journal of Biological Chemistry 66:375-400.

GONZÁLEZ, A. R.y V. NÚÑEZ REGUEIRO, 1960. Preliminary report on archaeological research in Tafí del Valle, N.W. Argentina. Akten del 34 Internationalen Americanisten Kongresses 34: 485-496.

KORSTANJE, A., 2005. La organización del trabajo en torno a la producción de alimentos en sociedades agropastoriles formativas (provincia de Catamarca, Argentina). Tesis Doctoral. Instituto de Arqueología y Museo, Facultad de Ciencias Naturales e Instituto Miguel Lillo, Universidad Nacional de Tucumán, San Miguel de Tucumán.

2007. Territorios campesinos: Producción, circulación y consumo en los valles altos. En Producción y circulación prehispánicas de bienes en el sur andino, E. Nielsen, C. Rivolta, V. Seldes, M. Vázquez y P. Mercolli (Eds.), pp. 191-223. Editorial Brujas, Córdoba.

2010. Producción y consumo agrícola en el valle del Bolsón (1992-2005). En Arqueología de la agricultura: Casos de estudio en la región andina argentina, A. Korstanje y M. Quesada (Eds.), pp. 48-75. Ediciones Magna, San Miguel de Tucumán.

KORSTANJE, A. y P. CUENYA, 2008. Arqueología de la agricultura: Suelos y microfósiles en campos de cultivo del valle del Bolsón, Catamarca, Argentina. En Matices interdisciplinarios en estudios fitolíticos y de otros microfósiles, A. Korstanje y P. Babot (Eds.), pp. 133-147. BAR International Series 1870, Oxford.

LUPO, L., C. SÁNCHEZ, N. RIVERAy M. E. ALBECK, 2010. Primeras evidencias palinológicas de cultivos en Pueblo Viejo de Tucute. Período Tardío de la Puna de Jujuy. Noroeste Argentino. En Arqueología de la agricultura: Casos de estudio en la región andina argentina, A. Korstanje y M. Quesada (Eds.), pp. 166-177. Ediciones Magna, San Miguel de Tucumán.

OLISZEWSKY, N., 2009. El recurso maíz en sitios arqueológicos del Noroeste Argentino: El caso de la Quebrada de Los Corrales, El Infiernillo, Tucumán. Treballs d'Etnoarqueologia 7: 83-96.

OLIVERA, D., P. TCHILINGUIRIAN y L. GRANA, 2004. Paleoambiente y arqueología en la Puna Meridional argentina: Archivos ambientales, escalas de análisis y registro arqueológico. Relaciones de la Sociedad Argentina de Antropología XXIX: 229-247.

2008. Las primeras poblaciones agropastoriles en la Puna Meridional argentina: Aportes desde la geoarqueología. En Problemática de la arqueología contemporánea. XV Congreso Nacional de
Arqueología Argentina, A. Austral y M. Tamagnini (Comps.), vol. 2, pp. 31-35. Río Cuarto.

PEREA, C., 1994. Mapa de vegetación del valle de Santa María, sector oriental (Tucumán, Argentina). Lilloa 37: 2.

QUESADA, M., 2010. Los límites de la autonomía doméstica en la agricultura de regadío. Antofalla y Tebenquiche Chico (s. III a XII DC). En Arqueología de la agricultura: Casos de estudio en la región andina argentina, A. Korstanje y M. Quesada (Eds.), pp. 130-143. Ediciones Magna, San Miguel de Tucumán.

RAPP, G. y C. HILL, 1998. Geoarchaeology. The earth science approach to archaeological interpretation. Yale University Press, Londres.

RIVOLTA, G., 1999. Investigaciones preliminares en el sitio arqueológico Los Cardones, provincia de Tucumán. XII Congreso Nacional de Arqueología Argentina, vol. 3, pp. 340-344. La Plata.

2007. Diversidad arqueológica y estructural en los diferentes sectores de la Quebrada de los Cardones: Sus espacios y recintos (valle de Yocavil, Tucumán). En Paisajes y procesos sociales en Tafí del Valle, P. Arenas, B. Manasse y E. Noli (Eds.), pp. 95-110. San Miguel de Tucumán.

2010. Espacios, recintos y “wankas" en la Quebrada de Amaicha-Los Cardones, Valle de Yocavil. XVII Congreso Nacional de Arqueología Argentina, vol. 2, pp. 777-782. Mendoza.

RIVOLTA, G. y J. SALAZAR, 2007. Los espacios domésticos y públicos del sitio Los Cardones (valle de Yocavil, provincia de Tucumán). En Procesos sociales prehispánicos en el sur andino. La vivienda, la comunidad y el territorio, A. Nielsen, C. Rivolta, V. Seldes, M. Vázquez y P. Mercolli (Eds.), pp. 123-142. Editorial Brujas, Córdoba.

ROLDÁN, J., M. M. SAMPIETRO y M. VATTUONE, 2005. Técnicas analíticas para el estudio de los suelos de sitios agrícolas prehispánicos. Primer Congreso Argentino de Arqueometría, pp. 6o69. Rosario.

ROLDÁN, J., M. M. SAMPIETRO, L. NEDER y M. VATTUONE, 2008. Efectos antrópicos del uso del suelo durante el Formativo en el valle de Tafí. Chungara, Revista de Antropología Chilena 40 (2): 161-172.

SAMPIETRO, M. M., 2002. Contribución al conocimiento geoarqueológico del valle de Tafí Tucumán (Argentina). Tesis Doctoral en Arqueología. Universidad Nacional de Tucumán e Instituto Miguel Lillo, San Miguel de Tucumán.

2007. El suelo como objeto de reflexión para la reconstrucción del contexto arqueológico. IV Reunión Internacional de Teoría Arqueológica en Suramérica, pp. 538-543. Catamarca. 
SAMPIETRO, M. M. y L. NEDER, 2011. Quaternary landscape evolution and human occupation in Northwestern Argentina. The Geological Society of London. Special Publications 352: 37-47.

SAYAGO, J. y M. COLLANTES, 1991. Evolución paleogeomorfológica del valle de Tafí (Tucumán, Argentina) durante el Cuaternario Superior. Bamberger Geographische Schriften 11: 109-124.

SOMONTE, C., 2009. Espacios persistentes y producción lítica en Amaicha del Valle, Tucumán. Tesis Doctoral. Facultad de Filosofia y Letras, Universidad de Buenos Aires, Buenos Aires.

SOMONTE, C. y C. BAIED, 2011. Recursos líticos, aprovisionamiento y aspectos temporales de fuentes de abastecimiento en Amaicha del Valle, Tucumán, Argentina. Comechingonia 14 (1): 97-113.

SOSA, J., 1996-97. Teledetección arqueológica en Amaicha del Valle (Tucumán): La ocupación Formativa. Cuadernos del INAPL 17: 275-292.

1999. Teleprospección arqueológica en Amaicha del Valle (departamento de Tafí del Valle, Tucumán). XII Congreso Nacional de Arqueología Argentina, vol. 3, pp. 358-365. La Plata.

2001. Arqueología de Amaicha del Valle (Tucumán): La ocupación en el período de Desarrollo Regional. Mundo de Antes 2: 75-93.
STRECKER, M., 1987. Late Cenozoic landscape in Santa María valley, Northwestern Argentina. Tesis Doctoral. Cornell University, Ithaca, Nueva York.

TARRAGÓ, M., 2000. Chacras y pukara. Desarrollos sociales tardíos. En Nueva Historia argentina. Los pueblos originarios y la Conquista, M. Tarragó (Ed.), pp. 257-300. Editorial Sudamericana, Buenos Aires.

TCHILINGUIRIAN, P. y D. OLIVERA, 2010. Agricultura, ambiente y sustentabilidad agrícola en el desierto: El caso Antofagasta de la Sierra (Puna argentina, $26^{\circ} \mathrm{S}$ ). En Arqueología de la agricultura: Casos de estudio en la región andina argentina, A. Korstanje y M. Quesada (Eds.), pp. 104-129. Ediciones Magna, San Miguel de Tucumán.

VAN BREEMEN, N. y P. BUURMAN, 2003. Soil Formation. Kluwer Academic Publishers, Nueva York.

WALKLEY, A. y A. BLACK, 1934. An examination of the Degtjareff method for determining soil organic matter and a proposed modification of the chromic acid titration method. Soil Science 37: 29-38.

WILLIAMS, V., A. KORSTANJE, P. CUENYA y M. P. VILLEGAS, 2010. La dimensión social de la producción agrícola en un sector del Valle Calchaquí Medio. En Arqueología de la agricultura: Casos de estudio en la región andina argentina, A. Korstanje y M. Quesada (Eds.), pp. 178-207. Ediciones Magna, San Miguel de Tucumán. 